\title{
IMPLEMENTASI AUGMENTED REALITY PADA MEDIA PROMOSI PENJUALAN RUMAH
}

\author{
Putu Bagus Adidyana Anugrah Putra a,1,* \\ a Jurusan Teknik Informatika, Fakultas Teknik, Universitas Palangka Raya, Kampus UPR Tunjung Nyaho, Palanglangka \\ Raya, Kalimantan Tengah, Indonesia \\ ${ }^{1}$ putubagus@it.upr.ac.id*; \\ * corresponding author
}

\section{ARTICLE INFO}

Keywords

Augmented Reality

Waterfall

\begin{abstract}
The development of the industry in Indonesia has been very broad until now, it can be seen from the varied types of products produced by the company. The level of competition in product sales at companies is increasing. Increased competition in product sales can be seen from the number of exhibition events that aim to increase product sales of each company. However, the sales technique is still classified as traditional and has shortcomings in marketing, especially for marketing housing promotions that exist today. Therefore, with the rapid development of technology at this time, the real form of the house promoted by the company can be helped by using Augmented Reality technology, which will help the buyer to get a clear and clear picture of the shape and condition of the house in 3D. The development of this application uses the waterfall method with stages, (1) Requirement Analysis, (2) System Design, (3) Implementation, (4) Integration and testing and (5) Operation \& Maintenance. This research resulted in an application that uses Augmented Reality technology aimed at companies in order to facilitate housing marketing where buyers can clearly see the original picture of the house being promoted in 3D.
\end{abstract}

\section{Pendahuluan}

Perkembangan industri di Indonesia sudah sangat luas sampai saat ini, hal tersebut dapat dilihat dari berbagai jenis variatif produk yang dihasilkan oleh perusahaan, tetapi yang menjadi kendala adalah tingkat persaingan pun semakin meningkat, oleh karena itu salah satu faktor penting adalah marketing atau bagian penjualan, selain menerapkan sistem direct selling tidak sedikit perusahaan yang menerapkan sistem penjualan melalui event-event pameran untuk meningkatkan penjualan produk dari masing-masing perusahaan.

Teknik marketing yang tersebut masih tergolong tradisional dan mempunyai kekurangan dalam hal pemasaran perumahan yang ada. Kekurangannya antara lain adalah kurang terlihatnya bentuk nyata dari rumah tersebut, sehingga menyulitkan pembeli yang ingin melihat bentuk rumah. Jika lokasi bagian pemasaran jauh dari lokasi perumahan, contohnya sedang berada di pameran, maka pembeli hanya akan melihat bentuk 2 dimensi. Teknik pemasaran saat ini sudah banyak yang menggunakan miniatur rumah, namun miniatur rumah yang dapat dilihat kurang interaktif. Pembeli hanya dapat melihat bentuk luar dari rumah dan bagian dalam rumah masih belum dapat terlihat.

Teknologi berbasis Augmented Reality (AR) sudah banyak digunakan pada saat ini, dimana dengan teknologi tersebut dapat menambahkan benda-benda maya, baik itu berbentuk 2 dimensi maupun 3 dimensi ke dalam lingkungan nyata yang ditampilkan secara real time dan bersamaan dengan menggunakan bantuan perangkat keras yaitu kamera.[1] Dengan penggunaan teknologi berbasis Augmented Reality ini dapat diimplementasikan sebagai alat bantu untuk media visualisasi bentuk rumah di PT. Ciptajasa Gita Pratama, sehingga calon pembeli dapat memperoleh gambaran secara pasti dan jelas dari bentuk serta kondisi rumah sebenarnya, karena selama ini yang biasa digunakan untuk visualisasi adalah media-media berbentuk 2 dimensi seperti foto dalam bentuk brosur yang 
tidak dapat memberikan gambaran atau sudut pandang secara keseluruhan dari rumah yang diperlihatkan.

\section{Metodologi Penelitian}

Model yang digunakan merupakan suatu hasil dari siklus hidup pengembangan perangkat lunak Model Waterfall [2] yaitu pada tahap analisis, desain, implementasi dan pengujian. Berikut ini merupakan beberapa tahapan penelitian, yaitu:

1) Studi Pustaka dan Observasi

Metode ini melakukan studi pustaka terhadap buku, jurnal ilmiah nasional dan internasional sebagai pendukung dalam penelitian.[3] Observasi dilakukan untuk mengambil data-data untuk titik dan berapa besar radius yang diperlukan untuk menandakan suatu ruangan yang nantinya akan dijadikan area untuk mengeluarkan informasi.

2) Analisis Sistem

Proses pencarian kebutuhan difokuskan pada software untuk mengetahui sifat dari aplikasi yang akan dibuat, pemodelan proses bisnis menggunakan Data Flow Diagram (DFD) dan Entity Relationship Diagram (ERD).[4] [5]

3) Desain Sistem

Proses ini digunakan untuk membuat blueprint software seperti, perancangan basis data dan perancangan interface.[6][7]

4) Implementasi

Proses ini akan dilakukan pembuatan perangkat lunak sesuai dengan perancangan basis data dan antar muka yang telah dilakukan pada tahap sebelumnya.[8]

5) Pengujian Sistem

Proses pengujian akan dilakukan dengan Blackbox Testing. Pengujian BlackBox adalah pengujian aspek fundamental sistem untuk menguji dan melihat kesalahan yang ada pada program maupun fungsi dari system.[9]

\section{Hasil dan Pembahasan}

\subsection{Bisnis Proses Sistem}

1) User diberikan brosur yang telah diisi marker lalu user men-download dan meng-install aplikasi.

2) Calon pembeli dapat melihat model $3 d$ dengan cara men-scan marker yang ada pada brosur menggunakan aplikasi tersebut.

3) Marker yang terdeteksi maka akan menampilkan $3 \mathrm{~d}$ model rumah yang dipilih calon pembeli.

4) Calon pembeli yang sudah merasa cocok dengan rumah yang ingin dibeli maka calon pembeli akan menanyakan informasi lebih lanjut. 


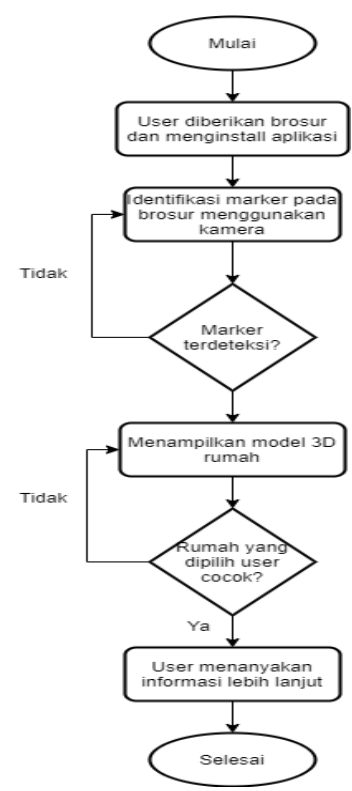

Gambar 1. Flowchart sistem

\subsection{Usecase Diagram}

Diagram usecase menggambarkan fungsi-fungsi yang ada pada sistem. Diagram ini lebih berfokus pada fitur-fitur sistem dari sudut pandang pihak luar, yang dalam hal ini adalah pengguna aplikasi.

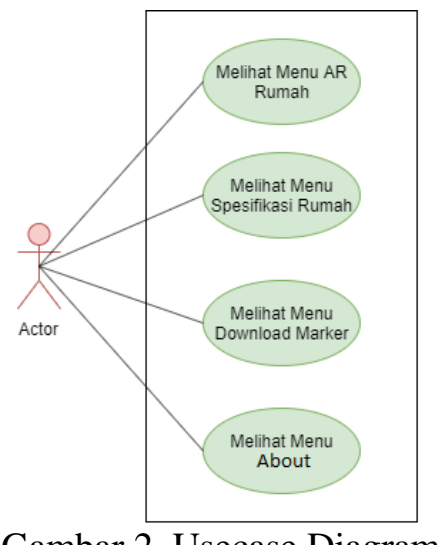

Gambar 2. Usecase Diagram

Pada gambar diatas menggambarkan fitur-fitur yang dapat diakses oleh pengguna. Pengguna dapat mengakses semua menu yang terdapat dalam aplikasi ini. Yaitu menu AR Rumah, menu Spesifikasi Rumah, menu Download Marker, dan menu Kontak

\subsection{Activity Diagram}

Diagram aktivitas ini menggambarkan aktivitas pengguna saat masuk ke dalam menu AR Rumah. Pengguna dapat masuk ke sistem ini dengan menekan tombol menu AR Rumah yang terdapat pada menu utama 


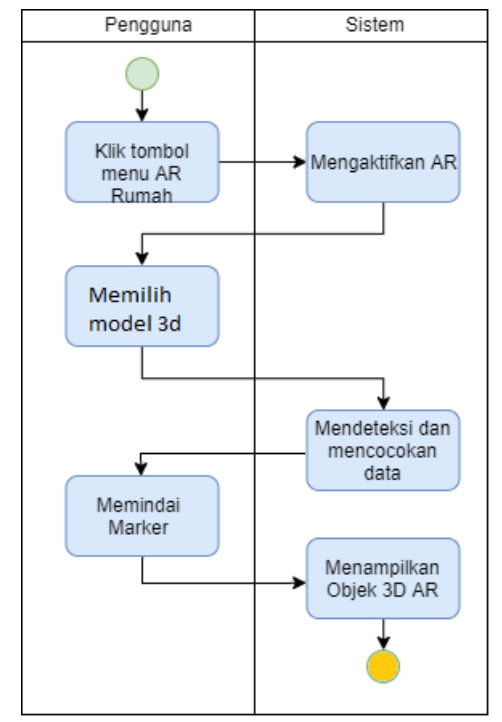

Gambar 3. Activity diagram

\subsection{Class Diagram}

Diagram kelas menggambarkan komponen-komponen pembentuk sistem yang berupa kelas atau interface, dan hubungan antar komponen tersebut.

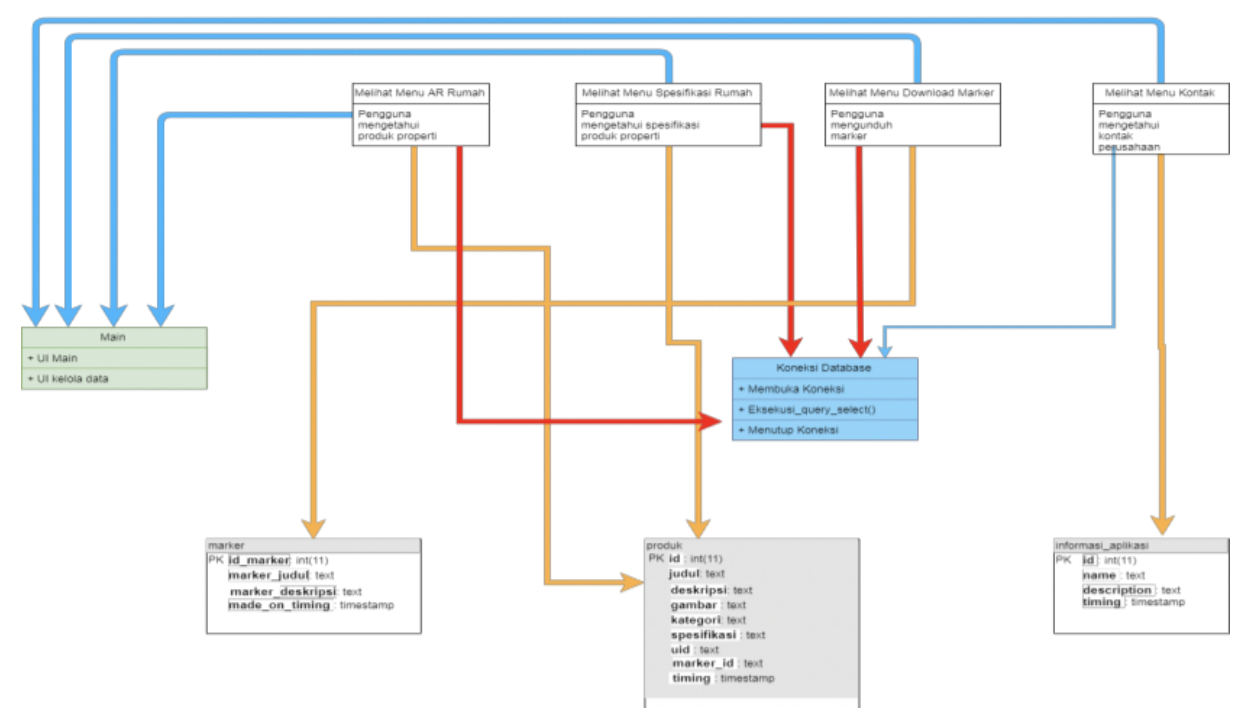

Gambar 4. Class Diagram

\subsection{Marker}

Penulis mengguanakan sebuah software bernama Photoshop untuk membuat file gambar yang diinginkan dengan software ini, penelitian ini membatasi ukuran gambar yang akan dibuat adalah berukuran 250px x 250px, yakni berukuran kotak yang mana gambar yang dibuat adalah gambar yang memiliki warna hitam dan putih saja, sedangkan pola yang dibuat adalah tulisan teks berupa huruf "I" dan "B". 


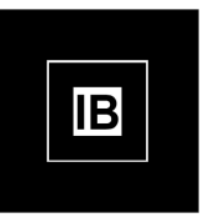

Gambar 5. Marker

Gambar diatas merupakan rancangan desain marker yang digunakan pada aplikasi Augmented Reality.

\subsection{Implementasi}

a) Halaman Menu utama

Pada awal user menjalankan aplikasi Augmented Reality akan ada muncul halaman menu Utama. Seperti terlihat pada gambar dibawah ini.

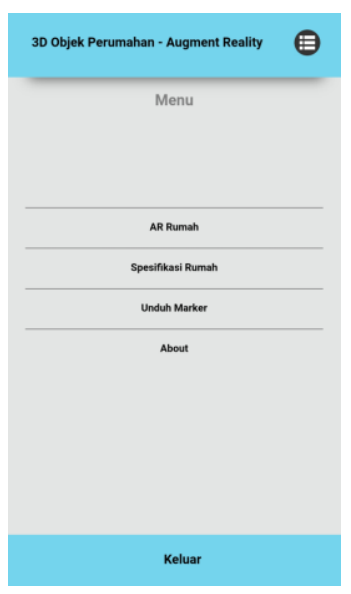

Gambar 6. Halaman menu utama

b) Tampilan menu AR Rumah

Pada halaman ini user dapat memilih tipe-tipe rumah yang ingin dipindai.

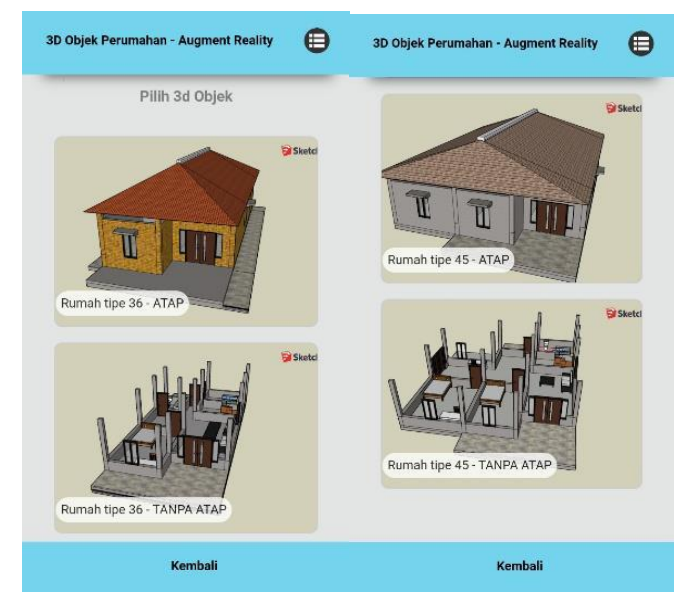

Gambar 7. Menu AR Rumah

c) Tampilan rumah dengan atap

Pada bagian menu AR rumah, user dapat memilih tipe-tipe rumah yaitu rumah dengan atap atau rumah tanpa atap. 


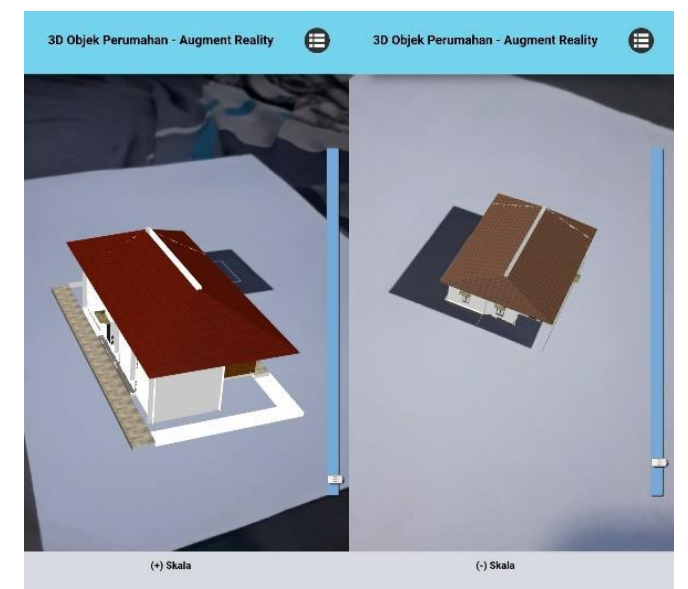

Gambar 8. Rumah dengan atap

d) Tampilan rumah tanpa atap

Pada bagian ini user memilih model rumah tanpa atap pada bagian menu AR Rumah

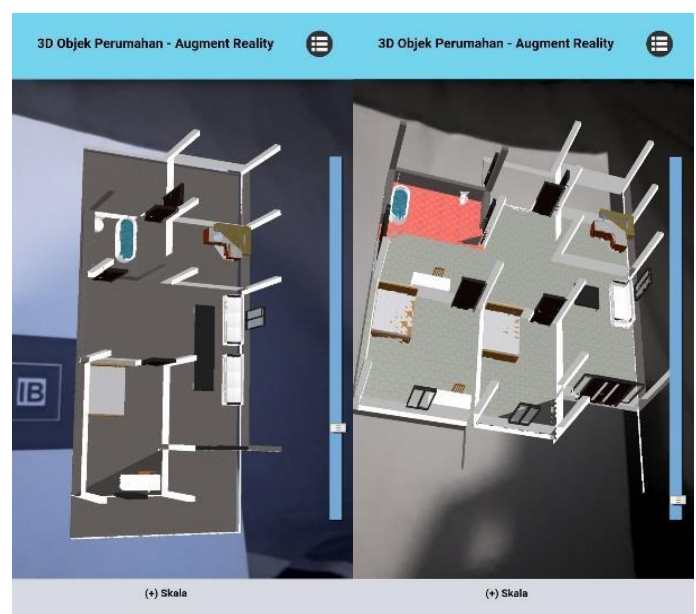

Gambar 9. Rumah tanpa atap

e) Tampilan menu spesifikasi rumah

Pada bagian menu spesifikasi rumah, user dapat menampilkan daftar lengkap dari rumah yang disediakan. 


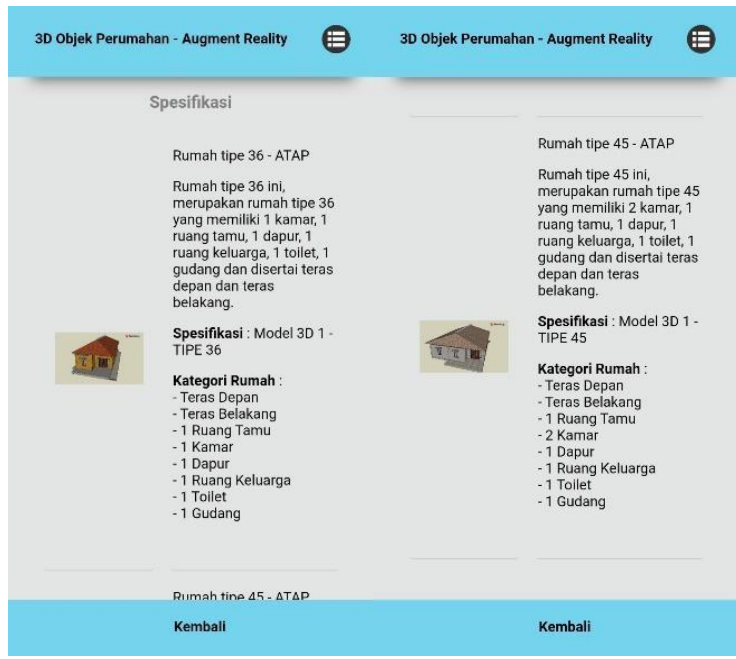

Gambar 10. Menu spesifikasi rumah

\subsection{Pengujian}

Tahap pengujan menggunakan blackbox testing dimana pada pengujian dengan metode ini hanya memfokuskan kepada fungsionalitas dari aplikasi yang dibuat.[10] Untuk tahapan pengujian blackbox ini, semua menu yang telah berjalan dengan baik dan masing-masing menu menunjukkan kinerja dari aplikasi ini dengan baik, seperti yang terlihat pada table berikut.

Tabel 1. Blackbox Testing

\begin{tabular}{|c|c|c|c|c|}
\hline No & Halaman & Proses & Hasil & Ket \\
\hline 1 & $\begin{array}{l}\text { Halaman menu } \\
\text { utama }\end{array}$ & Perangkat tersedia jaringan internet & $\begin{array}{l}\text { Aplikasi menampilkan daftar 3d objek dari } \\
\text { database server di halaman tombol "AR } \\
\text { Rumah" dan halaman "Spesifikasi Rumah". }\end{array}$ & OK \\
\hline 2 & $\begin{array}{l}\text { Halaman menu } \\
\text { utama }\end{array}$ & $\begin{array}{l}\text { Perangkat tidak tersedia jaringan } \\
\text { internet. }\end{array}$ & $\begin{array}{l}\text { Aplikasi tidak dapat mengambil data apapun } \\
\text { dari database server. }\end{array}$ & OK \\
\hline 3 & $\begin{array}{l}\text { Halaman menu } \\
\text { utama }\end{array}$ & Menekan tombol "AR Rumah" & $\begin{array}{l}\text { Aplikasi menuju halaman pemilihan 3d objek } \\
\text { "AR Rumah" dan scanner. }\end{array}$ & $\mathrm{OK}$ \\
\hline 4 & $\begin{array}{l}\text { Halaman menu } \\
\text { utama }\end{array}$ & $\begin{array}{l}\text { Menekan tombol "Spesifikasi } \\
\text { Rumah". }\end{array}$ & $\begin{array}{l}\text { Aplikasi menuju halaman "Spesifikasi } \\
\text { Rumah". }\end{array}$ & OK \\
\hline 5 & $\begin{array}{l}\text { Halaman menu } \\
\text { utama }\end{array}$ & Menekan tombol "Unduh Marker". & Aplikasi mengunduh gambar "Marker" & OK \\
\hline 6 & $\begin{array}{l}\text { Halaman menu } \\
\text { utama }\end{array}$ & Menekan tombol "Tentang Aplikasi" & Aplikasi menuju halaman "Tentang Aplikasi & OK \\
\hline 7 & $\begin{array}{l}\text { Halaman scanner / } \\
\text { AR Rumah }\end{array}$ & $\begin{array}{l}\text { Perangkat tidak memiliki fitur } \\
\text { kamera. }\end{array}$ & $\begin{array}{l}\text { Aplikasi menampilkan error perangkat tidak } \\
\text { memiliki kamera }\end{array}$ & OK \\
\hline 8 & $\begin{array}{l}\text { Halaman scanner / } \\
\text { AR Rumah }\end{array}$ & Menekan tombol "menu" & Aplikasi menampilkan halaman menu utama. & $\mathrm{OK}$ \\
\hline 9 & $\begin{array}{l}\text { Halaman scanner / } \\
\text { AR Rumah }\end{array}$ & $\begin{array}{l}\text { Menekan tombol " Slider" tanpa ada } \\
\text { 3d objek }\end{array}$ & $\begin{array}{l}\text { Aplikasi tidak dapat memperbesar atau } \\
\text { memperkecil 3d objek hasil pindai. }\end{array}$ & OK \\
\hline 10 & $\begin{array}{l}\text { Halaman scanner / } \\
\text { AR Rumah }\end{array}$ & $\begin{array}{l}\text { Menekan tombol " Slider" dengan ada } \\
\text { 3d objek. }\end{array}$ & $\begin{array}{l}\text { Aplikasi dapat memperbesar atau memperkecil } \\
\text { 3d objek hasil pindai. }\end{array}$ & OK \\
\hline 11 & $\begin{array}{l}\text { Halaman scanner / } \\
\text { AR Rumah }\end{array}$ & Menekan tombol "Skala" & $\begin{array}{l}\text { Aplikasi merubah hasil dari skala ukuran 3d } \\
\text { objek pada proses pemilihan tombol "Slider". }\end{array}$ & OK \\
\hline
\end{tabular}

\section{Kesimpulan}

Dalam mengimplementasi augmented reality pada media promosi penjualan rumah menggunakan metode pengembangan system waterfall dengan tahapan analysis, design, implementation, testing dan 
maintenance. Implementasi augmented reality pada media promosi penjualan rumah menggunakan data konsep dari tipe-tipe rumah yang dimasukkan pada aplikasi berbasis augmented reality yaitu tipe 36 dan tipe 45 yang dibuat menggunakan program Sketchup 3D. Marker sebagai tanda untuk memunculkan objek 3d pada aplikasi. Marker dibuat menggunakan Picture Maker dan dimasukkan pada database agar dapat disimpan secara online. Pengujian system menggunakan metode blackbox dimana fungsionalitas program sudah berjalan sesuai dengan yang diinginkan.

\section{Daftar Pustaka}

[1] Azuma, Ronald T. 1997. Journal : "A survey of Augmented Reality”. Presence: Teleoperators and virtual Environment. Agustus 1997

[2] Pressman, S. Roger. 2010. Pendekatan Praktisi Rekayasa. Perangkat Lunak. Edisi 7. Penerbit Andi. Yogyakarta. Halaman 45 -. 46

[3] Widiatry, W. 2017. Rancang Bangun Website Sistem Informasi Praktikum Jurusan Teknik Informatika Univeritas Palangka Raya. Jurnal Saintekom. Vol 6, No 2, Maret 2017

[4] Putra, P. B. A. A., Sari, N. N. K dan Pranatawijaya, V. H. 2017. Analisis Dan Desain Website Monitoring Konsultasi Bimbingan Kartu Rencana Studi (KRS). Jurnal Teknologi Informasi. Volume 11, Nomor 1, Januari 2017

[5] Pranatawijaya, V. H., Putra, P. B. A. A dan Gunawan, V. A. 2016. Pengembangan Perangkat Lunak Generate File Untuk Migrasi Data EPSBEDKe Format Table Feeder PDDIKTI. Jurnal Saintekom,Vol 6, No. 2, September 2016

[6] Pranatawijaya, V. H., Putra, P. B. A. A.,Widiatry, W dan Sari, N. N. K. 2018. Pengembangan Perangkat Lunak Generate File Akun Uang Kuliah Tunggal (UKT) Universitas Palangka Raya. Jurnal Saintekom, Vol 6, No. 2, September 2018

[7] Putra, P. B. A. A., Pranatawijaya, V. H., Widiatry, W., Lisa. 2017. Rancang Bangun Sistem Informasi Pencarian Data Mahasiswa Dan Dosen Pada Fakultas Hukum Universitas Palangka Raya. Jurnal Teknologi Informasi. Volume 11, Nomor 2, Agustus 2017

[8] Sari, N. N. K., Putra, P. B. A. A., dan Christian, E. 2019. Rancang Bangun Aplikasi Mobile Learning Tenses Bahasa Inggris. Volume 13, Nomor 2, Agustus 2019

[9] Pranatawijaya, V. H., Putra, P. B. A. A.,Widiatry, W dan Sari, N. N. K. 2019. Sistem Informasi Geografis Mencari Rute Lokasi Travel Di Kota Palangka Raya Berbasis Website. Jurnal Teknologi Informasi. Volume 13, Nomor 1, Januari 2019

[10]Harsh, B., Khanna, E dan Sudha. 2014. Black Box Testing based on Requirement Analysis and Design Specifications. International Journal of Computer Applications (0975 -8887). Volume 87- No.18, (February) 